\title{
High Thermal Dissipation of Normally off p-GaN Gate AlGaN/GaN HEMTs on 6-Inch N-Doped Low-Resistivity SiC Substrate
}

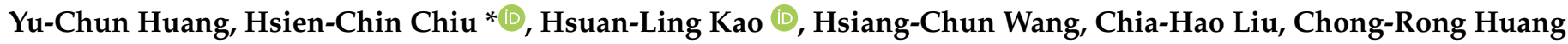 \\ and Si-Wen Chen
}

check for

updates

Citation: Huang, Y.-C.; Chiu, H.-C.; Kao, H.-L.; Wang, H.-C.; Liu, C.-H.; Huang, C.-R.; Chen, S.-W. High

Thermal Dissipation of Normally off p-GaN Gate AlGaN/GaN HEMTs on 6-Inch N-Doped Low-Resistivity SiC Substrate. Micromachines 2021, 12, 509 https://doi.org/10.3390/mi12050509

Academic Editor: Giovanni Verzellesi

Received: 31 March 2021

Accepted: 26 April 2021

Published: 1 May 2021

Publisher's Note: MDPI stays neutral with regard to jurisdictional claims in published maps and institutional affiliations.

Copyright: (c) 2021 by the authors. Licensee MDPI, Basel, Switzerland. This article is an open access article distributed under the terms and conditions of the Creative Commons Attribution (CC BY) license (https:/ / creativecommons.org/licenses/by/ $4.0 /)$.
Department of Electronics Engineering, Chang Gung University, Taoyuan 33324, Taiwan; james19961202@gmail.com (Y.-C.H.); snoopy@mail.cgu.edu.tw (H.-L.K.); smallflgt@hotmail.com (H.-C.W.); r3287133@gmail.com (C.-H.L.); gain525252@gmail.com (C.-R.H.); swchen@mail.cgu.edu.tw (S.-W.C.)

* Correspondence: hcchiu@mail.cgu.edu.tw

Abstract: Efficient heat removal through the substrate is required in high-power operation of AlGaN/GaN high-electron-mobility transistors (HEMTs). Thus, a SiC substrate was used due to its popularity. This article reports the electrical characteristics of normally off $\mathrm{p}-\mathrm{GaN}$ gate AlGaN/GaN high-electron-mobility transistors (HEMTs) on a low-resistivity $\mathrm{SiC}$ substrate compared with the traditional Si substrate. The p-GaN HEMTs on the SiC substrate possess several advantages, including electrical characteristics and good qualities of epitaxial crystals, especially on temperature performance. Additionally, the price of the low-resistivity SiC substrate is three times lower than the ordinary SiC substrate.

Keywords: p-GaN gate HEMT; normally off; low-resistance SiC substrate; temperature

\section{Introduction}

Gallium nitride high-electron-mobility transistors (HEMTs) have attracted increasing attention in the field of high-frequency and high-power device applications due to their high breakdown field, high mobility, and good thermal properties. However, they are naturally normally on devices. For high-power applications, off devices are normally desirable for system reliability [1]. Thus, several research works have been proposed to realize the normally off operation characteristics of AlGaN/GaN HEMTs such as fluorine base plasma treatment [2,3], an ultrathin barrier (UTB) [4], and gate-recessed structures [5,6].

Recently, GaN HEMTs with a p-GaN gate stack (p-GaN gate HEMTs) have been suggested as one of the candidates, in which a p-GaN layer on top of the AlGaN barrier depletes the 2D electron gas carriers in the channel [7-9]. The normally off $p-G a N$ gate $\mathrm{AlGaN} / \mathrm{GaN}$ high-electron-mobility transistor (HEMT) on a SiC substrate is expected to be a good choice for high-power switching components due to its high thermal conductivity, low resistivity, and high-voltage capability. Another advantage of using a SiC substrate is its lower lattice mismatch of $\sim 3 \%$ for $\mathrm{GaN}$ (that of $\mathrm{Si}$ is $\sim 17 \%$ ). Owing to the high material properties of gallian nitride and the $\mathrm{SiC}$ substrate, these devices are expected to operate in high-temperature environments [10].

Here, we analyzed the DC, breakdown, pulsed, and thermal measurement performances of AlGaN/GaN HEMTs with a p-GaN gate between low-resistivity SiC and ordinary Si substrates. Finally, the heat removal through the SiC substrate had the most outstanding performance.

\section{Experimental Procedures}

In this work, an epitaxy wafer was grown by metal organic chemical vapor deposition on 6-in n-doped low-resistivity $\mathrm{SiC}$ substrates, as shown in Figure 1a. A 650-nm-thick 
undoped GaN channel layer was grown on top of a 3.8- $\mu$ m-thick undoped GaN buffer layer. A 17.5-nm-thick undoped barrier (1.5-nm-AlN/15-nm-AlGaN/1-nm-AlN) layer was sandwiched between the GaN channel layer and a 75-nm p-type GaN cap layer. The fabrication process started with device isolation by an Ar implantation. The 5- $\mu \mathrm{m}$-long $\mathrm{p}-\mathrm{GaN}$ gate island was removed by $\mathrm{Cl}_{2} / \mathrm{BCl}_{3} / \mathrm{SF}_{6}$ dry etching and the etching depth was stopped by the $1 \mathrm{~nm}$ AlN etching stop layer. After dry etching, the source and drain ohmic contacts were prepared using the electron beam evaporation of a multilayered $\mathrm{Ti} / \mathrm{Al} / \mathrm{Ni} / \mathrm{Au}(25 \mathrm{~nm} / 120 \mathrm{~nm} / 25 \mathrm{~nm} / 150 \mathrm{~nm})$ sequence, patterned by a lift-off process, and annealed by a 30-s rapid thermal annealing (RTA) at $875{ }^{\circ} \mathrm{C}$ in ambient $\mathrm{N}_{2}$. Finally, a Ti/ $\mathrm{Au}(25 / 150 \mathrm{~nm})$ gate metal stack was deposited, and $100 \mathrm{~nm}$ of $\mathrm{SiN}$ was passivated by plasma-enhanced chemical vapor deposition (PECVD). The descriptions above were made by our own laboratory research process.
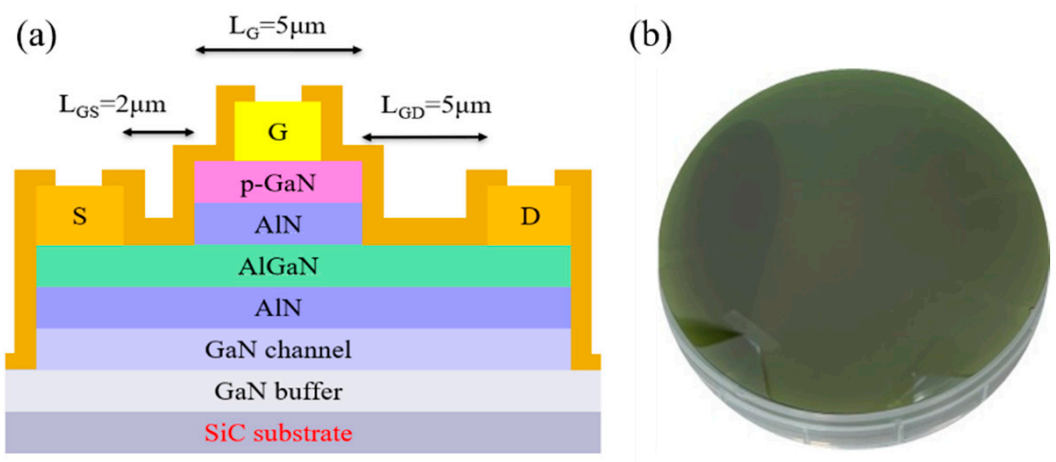

Figure 1. (a) Structure of $\mathrm{p}-\mathrm{GaN}$ gate HEMT on low-resistance substrate. (b) Outward appearance of low-resistance $\mathrm{SiC}$ wafer.

\section{Results and Discussion}

Figure 2a,b show the log-scale transfer $\left(\mathrm{I}_{\mathrm{DS}}-\mathrm{V}_{\mathrm{GS}}\right)$ and output $\left(\mathrm{I}_{\mathrm{DS}}-\mathrm{V}_{\mathrm{DS}}\right)$ characteristics of GaN on a low-resistivity SiC substrate HEMT (LRSiC-HEMT) and a Si substrate HEMT (Si-HEMT). As shown in Figure 2a, the off-state currents for the LRSiC-HEMT and Si-HEMT are $1.37 \times 10^{-5}$ and $5.2 \times 10^{-5} \mathrm{~mA} / \mathrm{mm}$ at $\mathrm{V}_{\mathrm{GS}}=0 \mathrm{~V}$, the $\mathrm{I}_{\mathrm{on}} / \mathrm{I}_{\text {off }}$ ratios are $1.5 \times 10^{8}$ and $1.85 \times 10^{6}$, and they deliver the normally off operation with a positive $\mathrm{V}_{\mathrm{TH}}$ of $3.2 \mathrm{~V}$ and $1.8 \mathrm{~V}$ defined at $\mathrm{I}_{\mathrm{D}}=1 \mathrm{~mA} / \mathrm{mm}$, respectively. In Figure $2 \mathrm{~b}$, the corresponding maximum drain current density $\left(\mathrm{I}_{\mathrm{Dmax}}\right)$ values are $131 \mathrm{~mA} / \mathrm{mm}$ and $108 \mathrm{mV} / \mathrm{mm}$ at a gate-to-source voltage $\left(\mathrm{V}_{\mathrm{GS}}\right)=8 \mathrm{~V}$ and a drain-to-source voltage $\left(\mathrm{V}_{\mathrm{DS}}\right)=10 \mathrm{~V}$. The $\mathrm{I}_{\mathrm{Dmax}}$ value of the LRSiC-HEMT was $28 \%$ higher than that of the Si-HEMT. Additionally, the LRSiC-HEMT also exhibits a lower on resistance $\left(\mathrm{R}_{\mathrm{ON}}\right)$ of $16 \Omega \cdot \mathrm{mm}$.

The breakdown voltage, $\mathrm{BV}$, of the devices is determined by the drain leakage current reaching $1 \mathrm{~mA} / \mathrm{mm}$. As shown in Figure 3, the off-state breakdown voltages and vertical breakdown voltages of LRSiC-HEMT and Si-HEMT are $325 \mathrm{~V}, 310 \mathrm{~V}, 413 \mathrm{~V}$, and $319 \mathrm{~V}$, respectively. Vertical breakdown voltage measurements were performed on both wafers by the grounded substrate, and the ohmic contact pattern was swept from $0 \mathrm{~V}$ up to the breakdown voltage; the size of the ohmic pattern is about $100 \times 100 \mu \mathrm{m}$. Although the epitaxy technology using the low-resistivity $\mathrm{SiC}$ substrate was not as stable, the on device performance and the substrate's breakdown voltages were still better than the traditional Si substrate.

Having confirmed the importance of the surface temperature distribution measurements, the temperature-time curve is shown in Figure 4 by using an infrared (IR) thermographic system with micro-Raman spectroscopy. On account of having much higher thermal conductivity, $\mathrm{SiC}$ could achieve an outstanding performance on heat dissipation. For the set of device measurements, $\mathrm{V}_{\mathrm{DS}}$ was held constant at $10 \mathrm{~V}$, while $\mathrm{I}_{\mathrm{DS}}$ was kept at $100 \mathrm{~mA} / \mathrm{mm}$ for $60 \mathrm{~s}$ and then waited for the device cool down for about $50 \mathrm{~s}$. As expected, the center of the gate area reached the highest temperature. As shown in Figure 4, following the time, the temperature gradient appears to increase. The temperature of LRSiC-HEMT 
was heated up to $34.4{ }^{\circ} \mathrm{C}$ and cooled down to $30{ }^{\circ} \mathrm{C}$ rapidly. On the contrary, Si-HEMT accumulated much more heat to reach $37.5^{\circ} \mathrm{C}$ and removed it slowly.

(a)

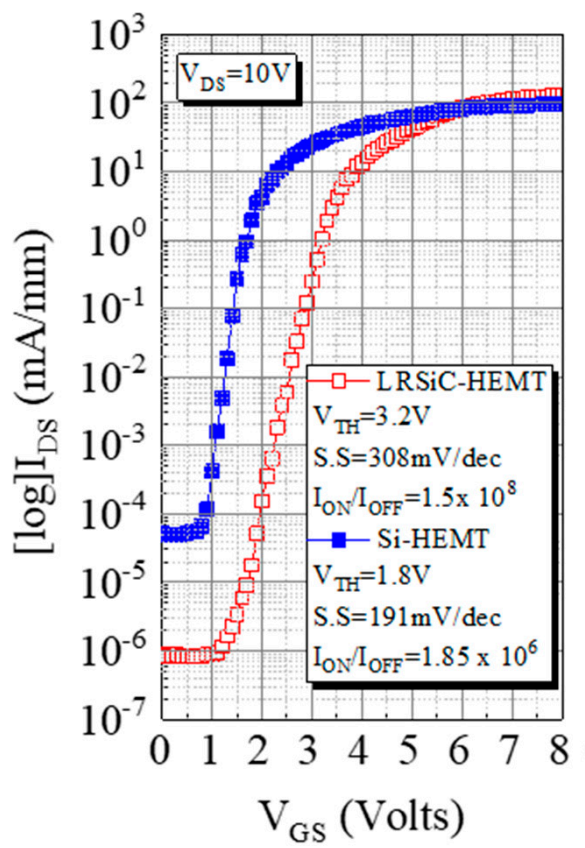

(b)

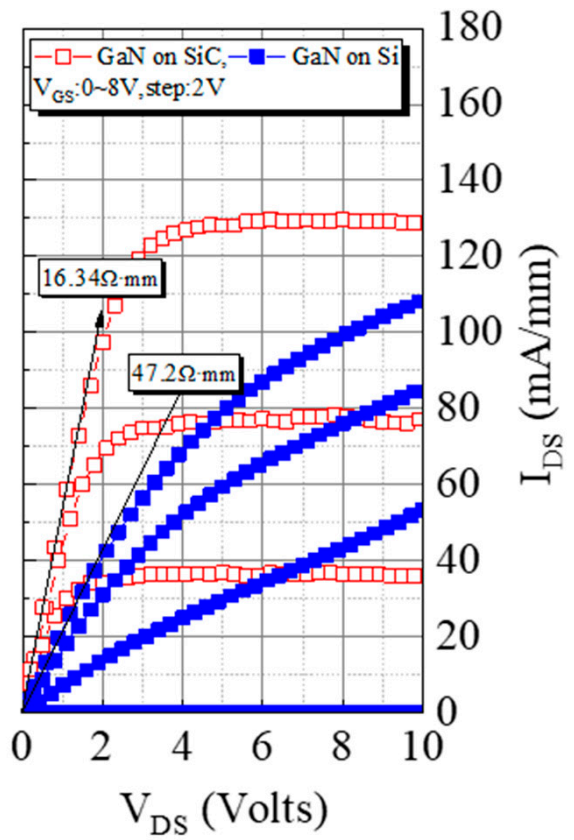

Figure 2. $\mathrm{I}-\mathrm{V}$ characteristics of LRSiC-HEMT and Si-HEMT with $\mathrm{L}_{\mathrm{GS}} / \mathrm{L}_{\mathrm{G}} / \mathrm{L}_{\mathrm{GD}} / \mathrm{W}_{\mathrm{G}}=2 / 5 / 5 / 100 \mu \mathrm{m}$. (a) Transfer $\mathrm{I}_{\mathrm{DS}}-\mathrm{V}_{\mathrm{GS}}$ characteristic. (b) Output $\mathrm{I}_{\mathrm{DS}}-\mathrm{V}_{\mathrm{DS}}$ characteristic.

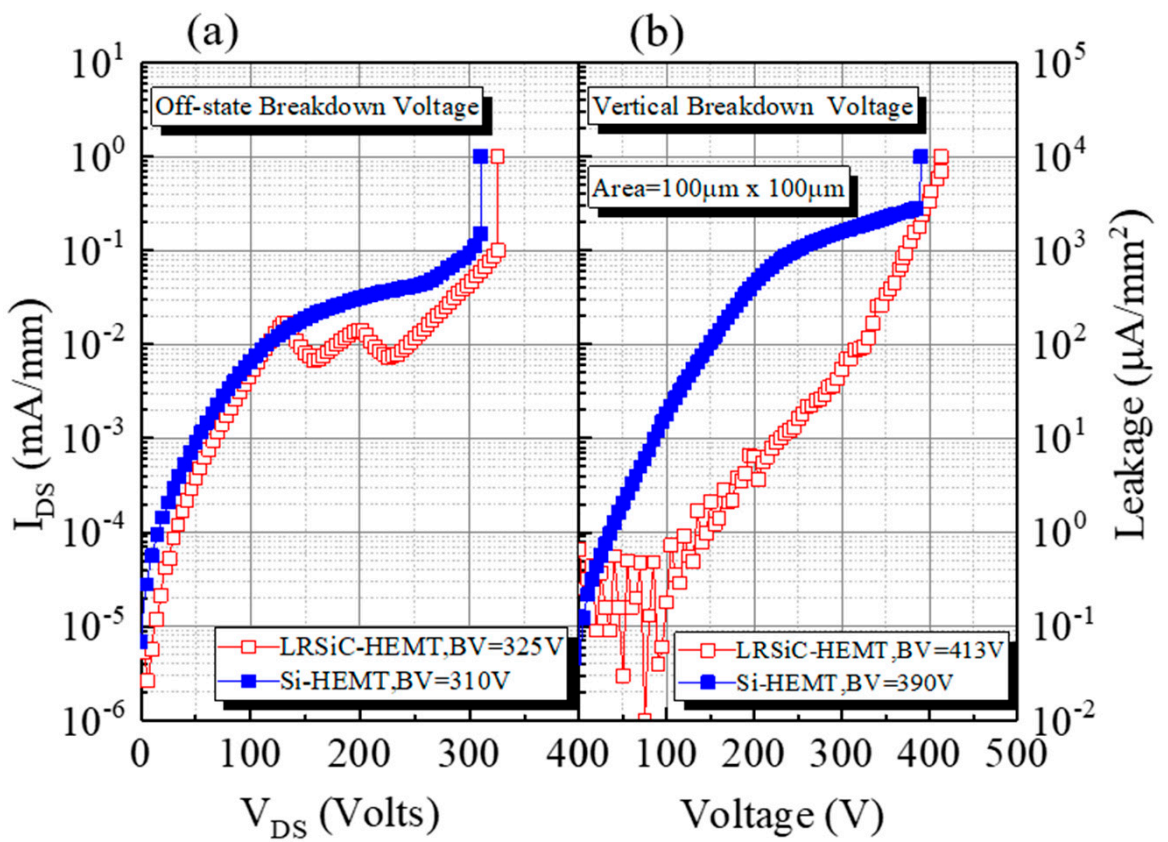

Figure 3. (a) Off-state breakdown voltage and (b) vertical breakdown voltage measurement. 


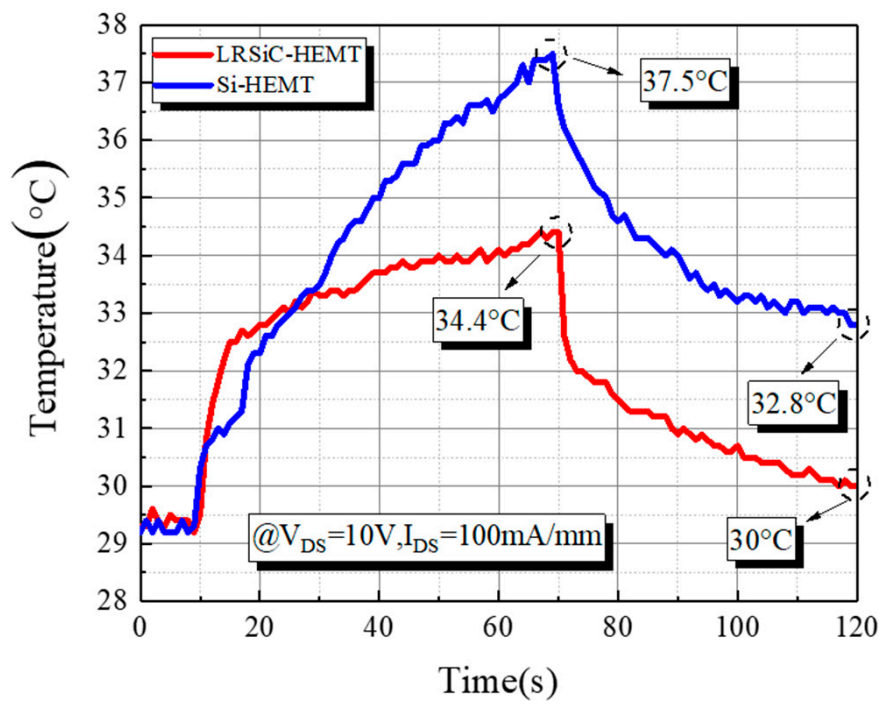

Figure 4. Temperature following the time, with the device operating for $60 \mathrm{~s}$ and cooling down for $50 \mathrm{~s}$.

To investigate the thermal stability of LRSiC-HEMT, transfer characteristics were measured from room temperature $\left(25^{\circ} \mathrm{C}\right)$ to $175^{\circ} \mathrm{C}$ with a $50{ }^{\circ} \mathrm{C}$ step (Figure $5 \mathrm{a}$ ). The device shows a good thermal stability with the $\mathrm{V}_{\mathrm{TH}}$ shifting less than $0.4 \mathrm{~V}$ up to $175^{\circ} \mathrm{C}$ (Figure $5 b$ ). $R_{\mathrm{ON}}$ increases by about 3.3 times, due to stronger phonon scattering at higher temperature [11].

(a)

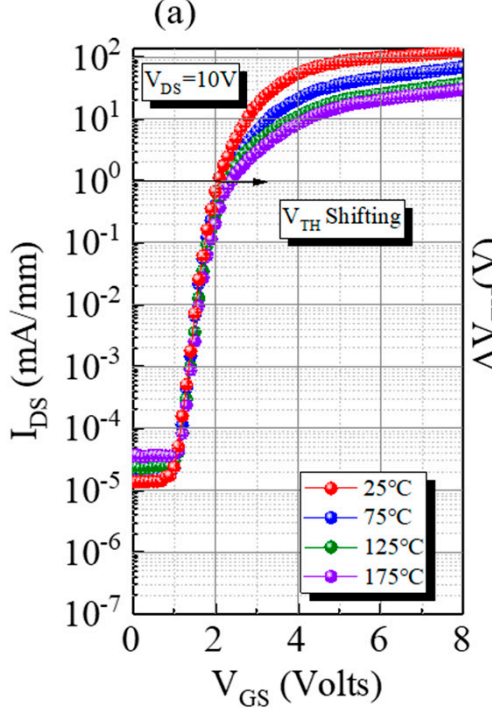

(b)

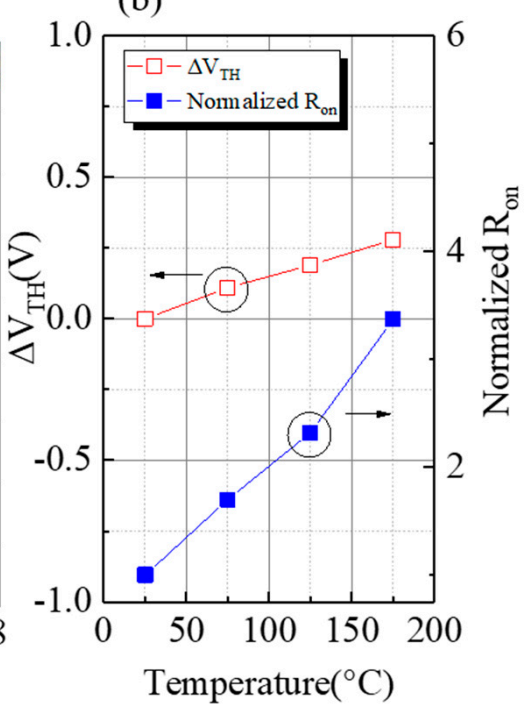

Figure 5. (a) Transfer characteristics of LRSiC-HEMT from 25 to $175{ }^{\circ} \mathrm{C}$; (b) T-dependence of $\mathrm{V}_{\mathrm{TH}}$ and $\mathrm{R}_{\mathrm{ON}}$.

To analyze the trapping/detrapping effect, the pulsed I-V characteristic and the dynamic $R_{\text {on }}$ ratio of LRSiC-HEMT were measured using a pulse width of $2 \mu$ s and a period of $200 \mu \mathrm{s}$. The carriers will be trapped in the buffer layer or near the surface which is in the AlGaN layer or passivation interface during the pulse measurement. Therefore, it will reduce the carrier density and make the resistance higher [12]. In this work, the $\mathrm{V}_{\mathrm{DSQ}}$ for LRSiC-HEMT is swept from 0 to $80 \mathrm{~V}$ with a step of $20 \mathrm{~V}$ in Figure 6. Clearly, the current collapse and the dynamic $\mathrm{R}_{\mathrm{ON}}$ ratio of Si-HEMT are both worse than LRSiC-HEMT. Additionally, being under relatively high stress led to an I-V slope decrease because of the defect trap density in the buffer layer and surface. In Figure 7, the dynamic $\mathrm{R}_{\mathrm{ON}}$ ratios are 6.8 times and 2.5 times at $\mathrm{V}_{\mathrm{DSQ}}=80 \mathrm{~V}$. 


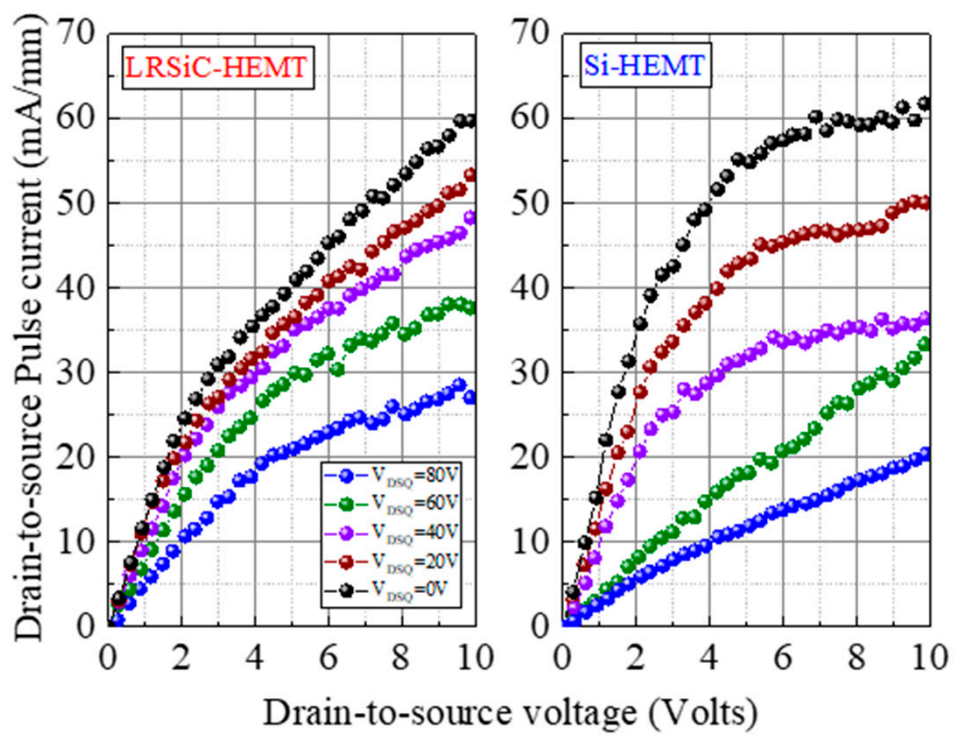

Figure 6. Pulsed $I_{D S}-V_{D S}$ characteristics from quiescent gate bias $\left(V_{G S Q}\right)$ point of $0 \mathrm{~V}$ with $2 \mu$ s pulse width and $200 \mu$ s pulse period. The quiescent drain bias $\left(V_{D S Q}\right)$ was then swept from 0 to $80 \mathrm{~V}$ (in $20-\mathrm{V}$ increments).

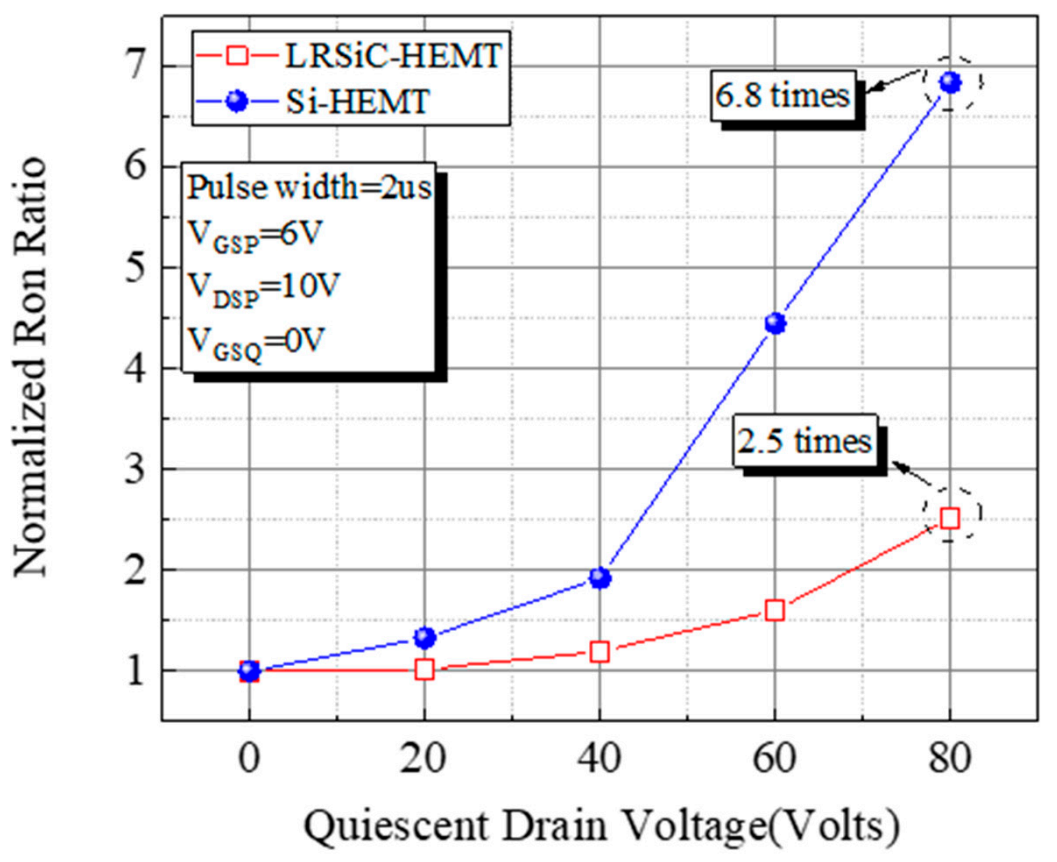

Figure 7. Dynamic $\mathrm{R}_{\mathrm{on}}$ ratio of LRSiC-HEMT and Si-HEMT.

\section{Conclusions}

In this work, normally off AlGaN/GaN high-electron-mobility transistors (HEMTs) with a p-GaN gate on a low-resistivity SiC substrate (LRSiC-HEMT) were developed. Comparing to Si-HEMT, LRSiC-HEMT obtained many advantages, such as a higher output current, higher off-state and vertical breakdown voltages, and a lower dynamic Ron ratio, especially in thermal performance. In addition, the price of the low-resistivity SiC substrate is much lower than the ordinary SiC substrate, which is shown in Table 1. Therefore, it holds promise to be an excellent choice to solve the heat problem and cost consideration for power devices. 
Table 1. Reference price and resistivity of low-resistivity SiC substrate and high-resistivity SiC substrate.

\begin{tabular}{ccc}
\hline & Reference Price & Resistivity $(\boldsymbol{\Omega} \cdot \mathbf{c m})$ \\
\hline $\operatorname{LRSiC}(6$ inch $)$ & USD1000 & $0.015 \sim 0.025$ \\
\hline HRSiC $(6$ inch $)$ & USD3000 & $>1 \mathrm{E} 5$ \\
\hline
\end{tabular}

Author Contributions: Data curation: Y.-C.H., C.-H.L.; formal analysis: H.-C.C.; funding acquisition: H.-L.K.; investigation: C.-R.H.; methodology: H.-C.W.; supervision: H.-C.C. and S.-W.C. All authors have read and agreed to the published version of the manuscript.

Funding: This research was funded by the Ministry of Science and Technology (MOST), Taiwan, R.O.C., grant number MOST 109-2218-E-182-001.

Conflicts of Interest: The authors declare no conflict of interest.

\section{References}

1. Khan, M.A.; Chen, Q.; Sun, C.J.; Yang, J.W.; Blasingame, M.; Shur, M.S.; Park, H. Enhancement and depletion mode GaN/AlGaN heterostructure field effect transistors. Appl. Phys. Lett. 1996, 68, 514-516. [CrossRef]

2. Chen, W.; Wong, K.-Y.; Chen, K.J. Monolithic integration of lateral field-effect rectifier with normally-off HEMT for GaN-onSi switch-mode power supply converters. In Proceedings of the IEEE IEDM, San Francisco, CA, USA, 15-17 December 2008; pp. 1-4.

3. Cai, Y.; Zhou, Y.; Chen, K.J.; Lau, K.M. Highperformance enhancement-mode AlGaN/GaN HEMTs using fluoridebased plasma treatment. IEEE Electron. Device Lett. 2005, 26, 435-437. [CrossRef]

4. Ohmaki, Y.; Tanimoto, M.; Akamatsu, S.; Mukai, T. Enhancementmode AlGaN/AlN/GaN high electron mobility transistor with low ON-state resistance and high breakdown voltage. Jpn. J. Appl. Phys. 2006, 45, 42-45. [CrossRef]

5. Oka, T.; Nozawa, T. AlGaN/GaN recessed MIS-gate HFET with high-threshold-voltage normally-off operation for power electronics applications. IEEE Electron. Device Lett. 2008, 29, 668-670. [CrossRef]

6. Kim, K.-W.; Jung, S.-D.; Kim, D.-S.; Kang, H.-S.; Im, K.-S.; Oh, J.-J.; Ha, J.-B.; Shin, J.-K.; Lee, J.-H. Effects of TMAH treatment on device performance of normally off Al2O3/GaN MOSFET. IEEE Electron. Device Lett. 2011, 32, 1376-1378. [CrossRef]

7. Uemoto, Y.; Hikita, M.; Ueno, H.; Matsuo, H.; Ishida, H.; Yanagihara, M.; Ueda, T.; Tanaka, T.; Ueda, D. Gate injection transistor (GIT) normally-off AlGaN/GaN power transistor using conductivity modulation. IEEE Trans. Electron. Devices 2007, 54, 3393-3399. [CrossRef]

8. Meneghini, M.; de Santi, C.; Ueda, T.; Tanaka, T.; Ueda, D.; Zanoni, E.; Meneghesso, G. Time- and field-dependent trapping in GaN-based enhancement-mode transistors with p-gate. IEEE Electron. Device Lett. 2012, 33, 375-377. [CrossRef]

9. Hilt, O.; Knauer, A.; Brunner, F.; Bahat-Treidel, E.; Wurfl, J. Normallyoff AlGaN/GaN HFET with p-type GaN gate and AlGaN buffer. In Proceedings of the ISPSD, Hiroshima, Japan, 6-10 June 2010; pp. 347-350.

10. Fleury, C. High temperature performances of normally-off p-GaN gate AlGaN/GaN HEMTs on SiC and Si substrates for power applications. Microelectron. Reliab. 2015, 55, 1687-1691. [CrossRef]

11. Wang, C. E-Mode p-n Junction/AlGaN/GaN (PNJ) HEMTs. IEEE Electron. Device Lett. 2020, 41, 545-548. [CrossRef]

12. Hwang, I.; Kim, J.; Chong, S.; Choi, H.S.; Hwang, S.K.; Oh, J.; Shin, J.K.; Chung, U.I. Impact of channel hot electrons on current collapse in AlGaN/GaN HEMTs. IEEE Electron. Device Lett. 2013, 34, 1494-1496. [CrossRef] 